\title{
Unsuccessful Practice of Percutaneous Endoscopic Gastrostomy in an Infant with Gastric Volvulus: a Case Report
}

\author{
Levent Duman', Behçet İlker Büyükyavuz', Mustafa Akçam² \\ ${ }^{1}$ Department of Pediatric Surgery, Faculty of Medicine, Süleyman Demirel University, Isparta, Turkey \\ ${ }^{2}$ Department of Pediatrics, Faculty of Medicine, Süleyman Demirel University, Isparta, Turkey
}

\begin{abstract}
Percutaneous endoscopic gastrostomy (PEG) is an easy and safe procedure for long-term enteral feeding in children with inadequate oral intake. Although PEG has been used for treatment of gastric volvulus in adults, there is a little relevant data for its use in children. Here, we report a 17-month-old male infant who was admitted to our hospital with a 1-month history of vomiting. Upper gastrointestinal contrast study revealed an organoaxial gastric volvulus. Then PEG was inserted for the purpose of nutritional support. Because the patient continued to vomit after feeding via gastrostomy, surgery was planned. Laparotomy revealed that the entry of the PEG tube was at the posterior wall of the stomach. The gastrostomy tube was removed, and the opening was repaired. Then the stomach was repositioned, and Nissen fundoplication and a Stamm gastrostomy at the anterior wall of the stomach were performed. The patient had no further episodes of vomiting after surgery and was discharged following an uneventful recovery period.
\end{abstract}

Key Words: Children, gastric volvulus, percutaneous endoscopic gastrostomy, complication

\section{Introduction}

Percutaneous endoscopic gastrostomy (PEG) is an endoscopic procedure that involves placing a tube into the stomach through the abdominal wall without laparotomy. It is used in patients unable to take in food by mouth for a prolonged period of time. This procedure is simple, safe, and rapid. Although PEG has been used for treatment of gastric volvulus in adults, there is a little relevant data for its safe use in children with gastric volvulus. Here, we report our experience of PEG insertion in an infant with gastric volvulus and discuss the feasibility of this procedure in children with gastric volvulus.

\section{Case Report}

A 17-month-old male infant was admitted to our hospital with a 1-month history of vomiting. He had been under valproate sodium and oxcarbazepine medication for afebrile generalized tonic-clonic seizures since 7 months of age.

The history of the patient revealed that he had been admitted to another medical center one month previously because of non-bilious vomiting after every feed, and had responded to medical measures without a need for surgical treatment. The patient was referred to our pediatric gastroenterology unit because of recurrent attacks of intractable vomiting after three weeks of his discharge from the hospital. On admission, his weight was found to be below the $10^{\text {th }}$ percentile. Upper gastrointestinal contrast study revealed an organoaxial gastric volvulus and gastro-esophageal reflux (Fig. 1). Because medical anti-reflux therapy (sodium alginate, omeprazole and metoclopramide) failed to control symptoms, PEG was inserted using the original "pull" technique under general anesthesia by a pediatric gastroenterologist for the purpose of nutritional support. His vomiting continued after every feed via gastrostomy during the follow-up period. Therefore, an elective operation was planned, and a jejunal feeding tube was inserted through the existing gastrostomy tube to facilitate weight gain until the operation which was performed one month later. Laparotomy revealed that the gastrostomy tube had passed through the gastrocolic omentum, and the entry of the gastrostomy tube was at the posterior wall of the stomach (Fig. 2). The gastrostomy tube was removed, and the opening was repaired. Then the stomach was repositioned, a Stamm gastrostomy at the anterior wall of the stomach was performed, and a Nissen fundoplication was added to the operation. The child made an uneventful postoperative recovery. Enteral nutrition was started after one week, and he was discharged 2 weeks later. He had no further episodes of vomiting and his weight gain was adequate during the 1-year follow-up period.

\section{Discussion}

Gastric volvulus is defined as an abnormal rotation of the stomach of more than $180^{\circ}$ around an axis (1). It is seen both in children and elderly patients; however it is an uncommon clinical entity in infants. Although the treatment of gastric volvulus in children is surgical, endoscopic reduction can be attempted in selected patients. 


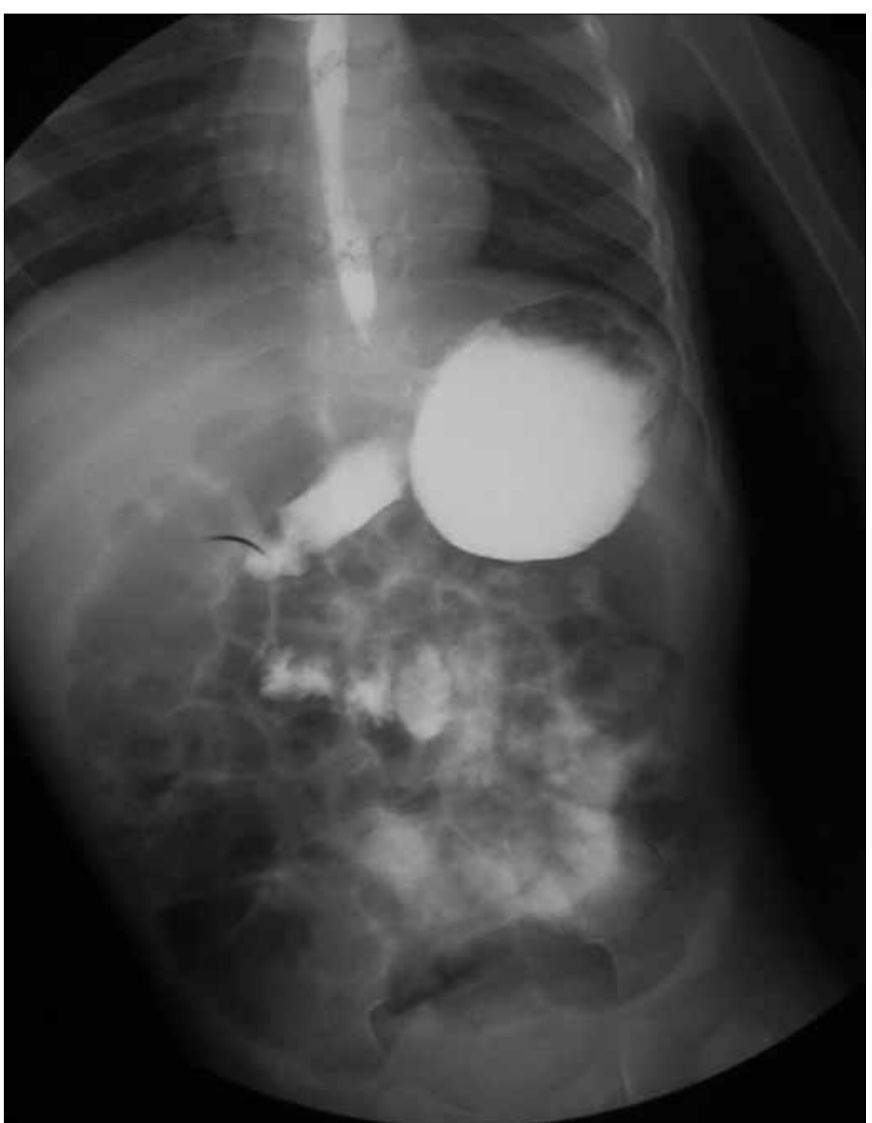

Figure 1. Upper gastrointestinal contrast study showing an organoaxial gastric volvulus and gastro-esophageal reflux

Since the introduction of PEG in 1980 by Gauderer et al. (2), this globally accepted procedure has become an alternative to surgical gastrostomy. It was used for the first time to deliver nutritional support to children with severe neurological disability (2). Other applications of PEG include long-term gastric decompression, nutritional support to children with malignancy and chronic medical diseases, pancreatic pseudocyst drainage, delivery of pharmacotherapy, and treatment of gastric volvulus (3).

Although PEG has been used for the treatment of gastric volvulus in adults, there is only a limited experience with the procedure in children with gastric volvulus. More recently, laparoscopic and endoscopic approaches have also been combined to better assess the intraluminal and intraabdominal status of the stomach as well as its position before, during, and after fixation (4). Before PEG placement, a multidisciplinary team of a pediatric gastroenterologist and pediatric surgeon should discuss the best approach.

In 1985, Eckhauser et al. (5) described a double PEG method for fixation of the stomach after reduction of a gastric volvulus by advancing the endoscope beyond the point of torsion, then rotating it to untwist the stomach. The feasibility of this procedure in adults has been demonstrated with certainty, but it is unknown in children. To the best of our knowledge, there is only one report of an infant with congenital gastric volvulus who was treated by fixing the stomach to the abdominal wall by PEG. Although there was a major reduction in vomiting with subsequent adequate weight gain, this patient finally required surgical gastropexy because of refractory singultus (6). However, it is evident that, if the gastric volvulus is not reduced during PEG insertion, symptoms will continue until correction of the pathology as in our patient.

One more specific complication of PEG is a gastroenteric fistula. Patwardhan et al. (7) reported a $3.5 \%$ incidence of this complication. In this series, the posterior wall of the stomach was the point of entry of the PEG catheter in all cases. Croaker and Najmaldin (8) observed that inflation of the stomach before insertion of PEG may cause rotation of the stomach, carrying the transverse colon anterior to the stomach, which may be responsible for some of the gastroenteric fistula after PEG insertion. Although this complication did not occur in our case, it is clear that the risk of gastroenteric fistula in patients with gastric volvulus is higher than in others because of the abnormal position of the stomach. However, Yu et al. (4) reported 15 children who had laparoscopic-assisted PEG with $0 \%$ incidence of major complications such as bowel injury; therefore laparoscopic-assisted PEG may be used to avoid this complication in children with gastric volvulus.

Although the insertion of PEG may cause gastroesophageal reflux (GER) (9), some reports in the literature suggest that there is no increased risk for the development of GER after PEG insertion (10). The therapeutic alternatives for GER with or without gastric volvulus are long-term administration of medical measures, medication with drugs, and surgery. Placement of a jejunostomy or jejunal feeding tube via the gastrostomy site described by Ponksy and Aszodi (11) is another alternative in patients with continuoust vomiting. Our case had GER before PEG insertion and the patient showed no improvement in his vomiting after PEG insertion, so a jejunal feeding tube was placed through the gastrostomy tube. Although few reports of this procedure in children have been published in the literature, we believe that this procedure may be useful in the case of GER after PEG insertion to enhance the quality of life until the corrective operation.

Different surgical procedures have been described in children with gastric volvulus. Although operative derotation and anterior gastropexy with correction of the associated pathology are well-established treatments for gastric volvulus, we performed Stamm gastrostomy for nutrition and fixation of the stomach and added Nissen fundoplication to treat and/ or prevent GER, because gastrostomy may initiate GER or worsen preexisting GER (12).

In conclusion, PEG is a well established technique for longterm enteral feeding in children, but there is only limited experience with the procedure in children with gastric volvulus which requires further experience. It is questionable whether or not PEG is harmless in children with gastric volvulust. We believe that this procedure may be attempted in selected patients in whom position of the stomach should be corrected before the insertion of the PEG tube. We suggest that surgical or laparoscopically assisted procedures should be preferred to prevent most of the major complications associated with the procedure. 


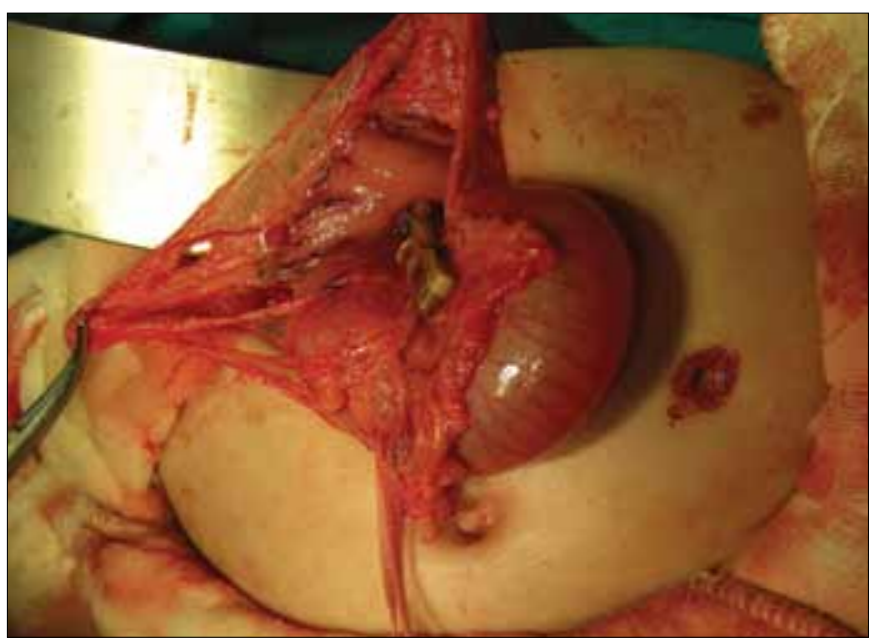

Figure 2. The operative finding showing twisting of the stomach and gastrostomy tube at the posterior wall of the stomach

\section{Conflict of Interest}

No conflict of interest was declared by the authors.

\section{References}

1. Tanner NC. Chronic and recurrent volvulus of the stomach. Am J Surg 1968;115:105-9. [CrossRef]

2. Gauderer MW, Ponsky JL, Izant RJ Jr. Gastrostomy without laparotomy: a percutaneous endoscopic technique. J Pediatr Surg 1980;15:872-5. [CrossRef]
3. Gauderer MW. Percutaneous endoscopic gastrostomy-20 years later: a historical perspective. J Pediatr Surg 2001;36:217-9. [CrossRef]

4. Yu SC, Petty JK, Bensard DD, Partrick DA, Bruny JL, Hendrickson RJ. Laparoscopic-assisted percutaneous endoscopic gastrostomy in children and adolescents. JSLS 2005;9:302-4.

5. Eckhauser ML, Ferron JP. The use of dual percutaneous endoscopic gastrostomy (DPEG) in the management of chronic intermittent gastric volvulus. Gastrointest Endosc 1985;31:340-2. [CrossRef]

6. Behrens R, Lang T, Muschweck H, Richter T, Hofbeck M. Percutaneous endoscopic gastrostomy in children and adolescents. J Pediatr Gastroenterol Nutr 1997;25:487-91. [CrossRef]

7. Patwardhan N, McHugh K, Drake D, Spitz L. Gastroenteric fistula complicating percutaneous endoscopic gastrostomy. J Pediatr Surg 2004;39:561-4. [CrossRef]

8. Croaker GDH, Najmaldin AS. Laparoscopically assisted percutaneous endoscopic gastrostomy. Pediatr Surg Int 1997;12:130-1. [CrossRef]

9. Grunow JE, al-Hafidh A, Tunell WP. Gastroesophageal reflux following percutaneous endoscopic gastrostomy in children. J Pediatr Surg 1989;24:42-5. [CrossRef]

10. Razeghi S, Lang T, Behrens R. Influence of percutaneous endoscopic gastrostomy on gastroesophageal reflux: a prospective study in 68 children. J Pediatr Gastroenterol Nutr 2002;35:27-30. [CrossRef]

11. Ponsky JL, Aszodi A. Percutaneous endoscopic jejunostomy. Am J Gastroenterol 1984;79:113-6. [CrossRef]

12. Jolley SG, Tunell WP, Hoelzer DJ, Thomas S, Smith El. Lower esophageal pressure changes with tube gastrostomy: a causative factor of gastroesophageal reflux in children? J Pediatr Surg 1986;21:624-7. [CrossRef] 